\title{
A Descriptive Study on the Civil Lawsuits of Medical Malpractice Occurred during Psychiatric Ward Treatment
}

\author{
Song li Ahn', Won Lee ${ }^{2}$, and Dong Ho Song ${ }^{3 凶}$ \\ ${ }^{1}$ Graduate School, Yonsei University College of Medicine, Seoul, Republic of Korea \\ ${ }^{2}$ Department of Nursing, Chung-Ang University, Seoul, Republic of Korea \\ ${ }^{3}$ Department of Psychiatry and Institute of Behavioral Science in Medicine, Yonsei University College of Medicine, Seoul, Republic of Korea
}

\begin{abstract}
Objective Medical accidents have resulted in actual harm for patients, been costly for health care system, and diminished trust for both patients and practitioners. The present study analyzed malpractice claims related to accidents in psychiatric inpatient units.

Methods This study analyzed defendants, cases and plaintiffs or patients characteristics, degrees of injury, and types of accidents in 85 civil malpractice suits filed from 2005 to 2015 with a focus on the methods and locations of suicides.

Results Most defendants were psychiatrists $(n=43)$. Of the 85 cases, $56(65.9 \%)$ were decided in favor of the plaintiff, most commonly on the grounds of negligence and violation of sound facility management principles. The most common diagnosis of patients was schizophrenia $(\mathrm{n}=31)$. The damages were deaths in 52 cases and injuries or other damages in the remaining 33 cases. The most common accident was suicide $(n=28)$, followed by escape attempts $(n=15)$. The most common suicide method was hanging $(n=21)$, which was usually committed in the private room using objects like door handles.

Conclusion To reduce medical accidents, medical staff should monitor high-risk patients closely and constantly. Sufficient numbers of well-trained personnel are required to meet this standard. Reducing environmental hazards such as removing anchor points and installing door locking systems will improve patient safety.

Psychiatry Investig 2020;17(9):865-870
\end{abstract}

Key Words Malpractice, Psychiatry, Inpatient, Patient safety, Suicide.

\section{INTRODUCTION}

There has recently been a significant increase in public awareness of medical error, since an important report on preventable medical errors had been published. ${ }^{1}$ Medical accidents have resulted in actual harm for patients, been costly for health care system, and diminished trust for both patients and practitioners.

More than half of medical error disputes are settled through mediation and arbitration, but the rest are litigated. ${ }^{2}$ Malpractice claims place a significant financial burden, time demands, emotional distress and moral pressure on the physicians who face them. ${ }^{3,4}$ Physicians often order more tests for patients than

Received: January 7, 2020 Revised: April 21, 2020

Accepted: June 1, 2020

$\triangle$ Correspondence: Dong Ho Song, MD, PhD

Department of Psychiatry and Institute of Behavioral Science in Medicine, Yonsei University College of Medicine, 50-1 Yonsei-ro, Seodaemun-gu, Seoul 03722, Republic of Korea

Tel: +82-2-2228-1620, Fax: +82-2-313-0891, E-mail: dhsong@yuhs.ac

(a) This is an Open Access article distributed under the terms of the Creative Commons Attribution Non-Commercial License (https://creativecommons.org/licenses/bync/4.0) which permits unrestricted non-commercial use, distribution, and reproduction in any medium, provided the original work is properly cited. is likely necessary, so this so-called defensive medicine trend drives up the cost of medical care. ${ }^{5}$ Psychiatrists also experience emotional distress after medical accident which may cause feelings of failure or morbid symptoms. ${ }^{6}$ Some psychiatrists even stop practicing altogether. ${ }^{7}$

This study analyzed malpractice lawsuit data to better understand the characteristics of accidents that occurred in psychiatric wards resulting in patient injury. Data about concluded lawsuit is a useful resource for studying medical accidents resulting in severe injuries. This study focused on ward environments of patient with suicide, because inpatient suicide can occur even when the patient is in under observation and only has access to limited materials and areas. ${ }^{8}$ This study also examined the characteristics of the defendants and case. This paper will suggest strategies for individual practitioner and institutions for preventing suicide and other accident that cause patient injuries in psychiatric ward.

\section{METHODS}

The databases of judgment search system of South Korea 
Supreme Court library were retrieved for the case number that had reached final judgment between January 2005 and December 2015, using the search terms "compensation for medical litigation," "neuropsychiatry," "psychiatry," "mental patient," and "psychiatric."

The initial search yielded 6,376 cases, of which 6,257 were excluded during the initial screening. The following were excluded from the study: 1) those alleging malpractice that occurred in outpatient clinic, nursing care center, oriental medicine hospital or residential facility; 2) those in which the alleged malpractice occurred during a consultation; and 3) those alleging the violation of involuntary admission rules. And 4 cases were excluded due to being not available and further 30 precedents were excluded after full text screening for the following reasons: outpatient suicide $(n=1)$, suicide after psychiatric consultation in nonpsychiatric inpatients $(\mathrm{n}=5)$, suicide in nonpsychiatric inpatients $(\mathrm{n}=3)$, deaths or injuries occurred in facilities other than hospitals $(n=11)$, dissatisfaction with treatment such as drug side effect and alleged misdiagnosis $(n=6)$, fall injury of psychiatric inpatient occurred in nonpsychiatric ward $(\mathrm{n}=1)$, not concluded case $(n=1)$, suicide on the day of discharge $(n=2) ; 85$ could be included for analysis (Figure 1).

Patient outcomes were categorized as either death or nonmortal injury. The International Classification for Patient Safety ("ICPS") classified degree of harm in increasing order of severity as none, mild, moderate, severe, and death. In order for the injury to qualify as death, the patient's death had to have been caused by and occurred shortly after the accident which was alleged to have caused the patient's injury. ${ }^{9}$ Due to limited precedent, death was defined as having occurred when the dead patient was discovered and after cardiopulmonary resuscitation and surgical treatment failed to revive them or if death occurred within six months of the accident in question due to complication caused by the accident, such as pneumonia. All other harm was defined as injury to define the severity. Accidents were categorized according to the standards followed in other studies and the ICPS. ${ }^{9-12}$ Jumpings from a height were classified as suicides, escape attempts, or jumps of unknown causes in accordance with patient's intent and the judges rulings.

The time at which the accidents in question occurred were categorized as occurring during the day or night and during the weekday or the weekend. The weekend was defined as 18:00 Fridays to 08:00 Mondays. Legal holidays were classified as weekends. There was insufficient information about facility shift, so the day shift was defined as 08:00 to 18:00 and the night shift as 18:00 to 08:00.

The management level was defined as whether the staff managed the patient by psychiatrist's order, or facility regula-

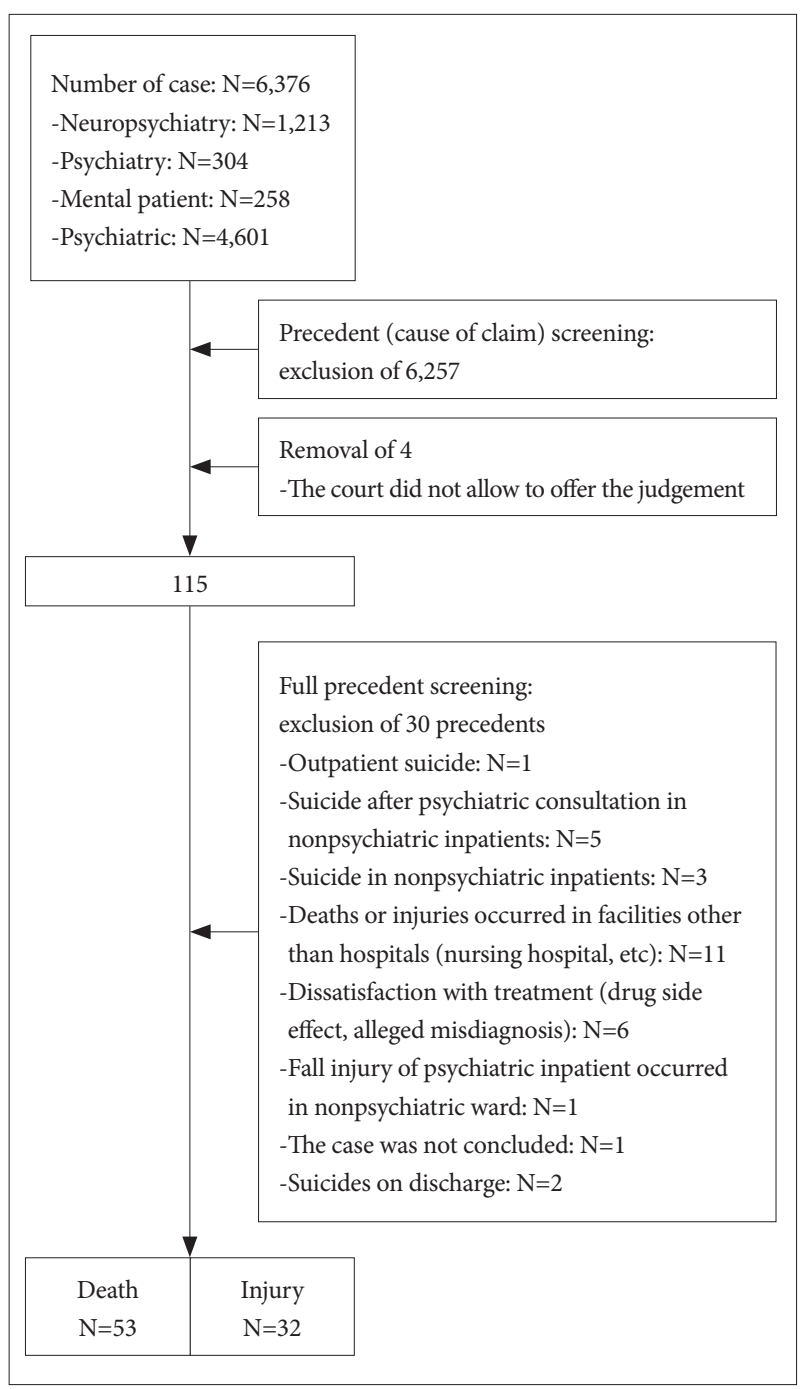

Figure 1. Flow chart of the study inclusion.

tion on high-risk patient. The precedent did not reveal whole records of hospitalization, so this study figured out by rulings about the duty of care.

This study had descriptive analysis of the patient and defendant characteristics such as patient's age, diagnoses, and the defendant's status. The legal proceeding has information of the amount, malfeasance that the judge ruled, and the limitation of liability ratio, so this study also described the result of civil lawsuit.

The present study's protocol was reviewed and approved by the Institutional Review Board of Yonsei University Severance Hospital (Y-2018-0144).

\section{RESULTS}

The mean patients age was $430.6 \pm 149.9$ months (range, 181-827 months) and patients were more frequently male $(n=38)$ than female $(n=23)$, but 24 cases did not described 
the patient's sex. Most patients had a single diagnosis $(\mathrm{n}=67)$ while others had two $(n=11)$, three $(n=2)$, and four $(n=1)$ diagnoses. The most common diagnosis was schizophrenia $(n=31)$. Other diagnoses included pathologic gambling, eating disorder, impulse control disorder, and conduct disorder (Table 1). The defendants were psychiatrists $(\mathrm{n}=43)$, medical legal entities $(n=28)$, educational entities $(n=13)$, attending physicians $(\mathrm{n}=5)$ and other health care providers $(\mathrm{n}=13)$ (These results were collected by multiple response) (Table 2).

Of the examined cases, 1 was adjudicated by the Supreme Court, 29 by appellate court, and 55 by trial courts, and 56 (65.9\%) found in favor of the plaintiff. The average initial amount claimed by the plaintiffs was KRW 223,766,865 $\pm 202,955,300$. The average amount awarded was KRW $62,765,780$. The limitations of liability ratio of the defendants were an average of $34.1 \% \pm 18.6$.

Findings in favor of the plaintiff were on the ground of negligence $(n=49)$ and violations of facility management duties $(n=23)$, insufficient provision of emergency treatment $(n=4)$, delayed diagnosis or transfer $(n=3)$, failure to obtain informed consent $(\mathrm{n}=1)$, violation of medical contract $(\mathrm{n}=1)$, the supervisor's liability to adult incompetent to tort responsibility $(\mathrm{n}=1)$, and the employer's liability $(\mathrm{n}=7)$. Some cases included findings of malfeasance on multiple grounds.

The majority of cases were about death $(n=53)$, while the rest were about injuries.

The most common type of accidents was suicide ( $\mathrm{n}=28$ ), followed by escape $(n=15)$, fall $(n=6)$, jumping out a window for an unknown cause $(n=6)$, drug side effect $(n=4)$, transport-related injury $(n=3)$, asphyxiation $(n=5)$, assault by another patient $(n=4)$, delayed treatment or transfer $(n=11)$ and restraint-related injury $(n=3)$. Hanging $(n=20)$ was by far the most common method which patients most commonly committed using their uniforms (Table 3). Bathrooms and showers were common locations for suicide and the ligature fixation points for hanging were taps, door hinges, and door handles. Of those who committed suicide, 14 had been hospitalized as suicide risks or were to have engaged in suicidal behaviors in the past. However medical staff failed to monitor 10 of these patients prior to their suicides (Table 4).

Accidents in which patients jumped from a height occurred because of unlocked doors in closed ward $(n=1)$ or the wards were open $(n=2)$ or patients were outside of the ward to walk or visit with others $(n=4)$. With regard to staff, they were focused on other patients, or they left doors open (Table 5).

Accidents occurred an average of $148.6 \pm 412.7$ days after admission. The median number of days after admission was 16 with a range of 1 to 2,214. Patients with depressive disorder had accidents an average of 33.2 days after admission while patients with schizophrenia had accidents an average of 268 days after admission. Accidents were more likely to occur at night than during the day and on weekdays than during the weekends (Table 6).

\section{DISCUSSION}

The accidents, plaintiffs, defendants, the damages and legal proceedings in civil suits that arose over injuries suffered by

Table 1. Characteristics of patients

\begin{tabular}{|c|c|c|c|}
\hline & $\begin{array}{l}\text { Total number of } \\
\text { accidents }\end{array}$ & $\begin{array}{l}\text { Number of } \\
\text { deaths }\end{array}$ & $\begin{array}{c}\text { Number of } \\
\text { injuries }\end{array}$ \\
\hline \multicolumn{4}{|l|}{ Sex (case) } \\
\hline Male:Female & $38: 23$ & $27: 14$ & $11: 9$ \\
\hline Unknown & 24 & 11 & 13 \\
\hline \multicolumn{4}{|l|}{ Age (month) } \\
\hline Mean \pm SD & $430.6 \pm 149.9$ & $438.9 \pm 136.4$ & $408.7 \pm 181$ \\
\hline Median & 414 & 448 & 336 \\
\hline \multicolumn{4}{|l|}{ Diagnosis } \\
\hline Schizophrenia & 31 & 21 & 10 \\
\hline Alcohol dependence & 22 & 15 & 7 \\
\hline Depression & 13 & 11 & 2 \\
\hline Personality disorder & 6 & 6 & 0 \\
\hline Bipolar disorder & 6 & 3 & 3 \\
\hline Dementia & 2 & 0 & 2 \\
\hline Organic disorder & 5 & 4 & 1 \\
\hline $\begin{array}{l}\text { Obsessive compulsive } \\
\text { disorder }\end{array}$ & 3 & 3 & 0 \\
\hline Intellectual disability & 2 & 1 & 1 \\
\hline Other & 9 & 3 & 6 \\
\hline Unknown & 4 & 1 & 3 \\
\hline Psychosis & 31 & 21 & 10 \\
\hline Non-psychosis & 50 & 30 & 20 \\
\hline
\end{tabular}

SD: standard deviation

Table 2. Characteristics of defendants

\begin{tabular}{lccc}
\hline & $\begin{array}{c}\text { Total number of } \\
\text { accidents }\end{array}$ & $\begin{array}{c}\text { Number of } \\
\text { deaths }\end{array}$ & $\begin{array}{c}\text { Number of } \\
\text { injuries }\end{array}$ \\
\hline $\begin{array}{l}\text { Psychiatrist } \\
\text { (administrator) }\end{array}$ & 43 & 22 & 21 \\
Attending physician & 5 & 3 & 2 \\
Medical legal entity & 28 & 18 & 10 \\
Educational entity & 13 & 8 & 5 \\
Other health care & 13 & 10 & 3 \\
provider & & 4 & 0 \\
University hospital & 4 & 42 & 24 \\
Hospital & 66 & 6 & 9 \\
Clinic & 15 & &
\end{tabular}


Table 3. Accidents causing injury

\begin{tabular}{lccc}
\hline \multicolumn{1}{c}{ Type } & $\begin{array}{c}\text { Total number of } \\
\text { accidents }\end{array}$ & $\begin{array}{c}\text { Number of } \\
\text { deaths }\end{array}$ & $\begin{array}{c}\text { Number of } \\
\text { injuries }\end{array}$ \\
\hline Suicide & 28 & 26 & 2 \\
$\quad$ Hanging & 20 & 19 & 1 \\
$\quad$ Jumping from a height & 7 & 6 & 1 \\
$\quad \begin{array}{l}\text { Burning } \\
\quad \text { Self-immolation) }\end{array}$ & 1 & 1 & 0 \\
Fall & 6 & 3 & 3 \\
Escape & 15 & 6 & 9 \\
Jumping for an & 6 & 3 & 3 \\
$\quad$ unknown cause & & & \\
$\begin{array}{l}\text { Drug side effect } \\
\text { Transport- } \\
\text { related injury }\end{array}$ & 4 & 3 & 1 \\
Asphyxiation & 3 & 2 & 1 \\
Assault by another & 5 & 3 & 2 \\
patient & 4 & 1 & 3 \\
$\begin{array}{l}\text { Delayed treatment } \\
\text { or transfer }\end{array}$ & 11 & 5 & 6 \\
Restraint-related injury & 3 & 0 & 3 \\
\hline
\end{tabular}

psychiatric ward inpatients were analyzed. In many of the cases it was concluded that patients had been injured due to negligence in patient and facility management, so this study's results have implications for how to prevent suicide and other accident that cause patient injuries in psychiatric ward. This study focused on suicide, because inpatient suicide can prevent when the patient in under proper observation and only access to safe environment. This study's findings can be used to change operations and guidelines of inpatient psychiatric units, by extension, of medical-surgical units when they care patients comorbid with unstable psychiatric disorder. ${ }^{13}$

This study found the most common suicide method was hanging, which was usually committed in the private room using objects like door handles. Other studies about environmental risk factors have emphasized anchor points in inpatient suicide, which were doors, door handles and hinges in $53.8 \%$ of cases. ${ }^{11}$ Restricting access to or removing anchor point could be an effective way to reduce the number of inpatient suicides. ${ }^{12}$ After the Department of Veterans affairs began using the Mental Health Environment of Care Checklist ${ }^{14}$ when designing or monitoring psychiatric wards, the suicide rate decreased dramatically from 4.2 to 0.74 per 100,000 . This

Table 4. Characteristics of suicides by hanging

\begin{tabular}{|c|c|c|c|c|c|}
\hline Location & Anchor point & Ligature & $\begin{array}{c}\text { Previous } \\
\text { suicidal act }\end{array}$ & $\begin{array}{l}\text { Subject to } \\
\text { monitoring }\end{array}$ & $\begin{array}{c}\text { Case found in favor } \\
\text { of plaintiff }\end{array}$ \\
\hline Bathroom & Door & Towel & No & No & No \\
\hline Bathroom & Hinge & Handkerchief & Yes & No & Yes \\
\hline Bathroom & Safety frame & Uniform & No & No & No \\
\hline Bathroom & Unknown & Uniform & Yes & Yes & No \\
\hline Bathroom & Safety bar & Jump rope & No & No & Yes \\
\hline Bathroom & Balustrade & Uniform & Yes & No & Yes \\
\hline Bathroom & Hand rail & Arm sling & Yes & No & Yes \\
\hline Bathroom & Window guard & Uniform & No & No & Yes \\
\hline Shower & Showerhead & Uniform & No & No & Yes \\
\hline Shower & Showerhead & Pillow cover & Yes & Yes & Yes \\
\hline Shower & Showerhead & Uniform & Yes & No & Yes \\
\hline Shower & Safety frame & Uniform & Yes & No & Yes \\
\hline Bedroom & Door handle & Uniform & No & No & Yes \\
\hline Bedroom & Bed or bed rail & Uniform & Yes & Yes & Yes \\
\hline Bedroom & Screw & Plastic bag & Yes & No & Yes \\
\hline Bedroom & Hinge & Towel & Yes & No & Yes \\
\hline Bedroom & Unknown & IV line & Yes & Yes & Yes \\
\hline Seclusion room & Door handle & Underclothing & No & No & Yes \\
\hline Seclusion room & Window frame & Restraint band & No & Yes & No \\
\hline Garden & Tree & Unknown & No & No & No \\
\hline
\end{tabular}

IV: intravenous 
Table 5. Characteristics of suicides by other methods

\begin{tabular}{|c|c|c|c|c|c|}
\hline Method & Location & Situation & $\begin{array}{c}\text { Previous } \\
\text { suicidal act }\end{array}$ & $\begin{array}{l}\text { Subject to } \\
\text { monitoring }\end{array}$ & $\begin{array}{l}\text { Case found in } \\
\text { favor of plaintiff }\end{array}$ \\
\hline \multirow{7}{*}{$\begin{array}{l}\text { Jumping from } \\
\text { a height }\end{array}$} & Hallway of visiting room of open ward & Visit & No & No & Yes \\
\hline & Bridge & Walk & No & No & Yes \\
\hline & Roof garden of open ward & Move & No & No & Yes \\
\hline & Roof garden & Walk & Yes & No & Yes \\
\hline & Veranda of bathroom of visiting room & Visit & Yes & No & Yes \\
\hline & Rehabilitation hospital & Move & Yes & No & Yes \\
\hline & Hallway & Move & No & No & Yes \\
\hline $\begin{array}{l}\text { Burning } \\
\text { (Self-immolation) }\end{array}$ & Smoking area & Smoking & No & No & Yes \\
\hline
\end{tabular}

effect was found to have persisted after five years. ${ }^{15}$

Sometimes facility modifications are not possible due to privacy concerns, so constant observation is an alternative method for reducing the number of suicides. Bathrooms and showers should be placed close to nurse stations and should be monitored by staff when high-risk patients are using them because security cameras cannot be used to monitor them. ${ }^{16}$ In this study, some staffs monitored patient with a history of suicidal behavior poorly. Previous studies have shown that patient under observation untowardly committed suicide. ${ }^{17}$ Other studies have found that observation staffs frequently breached procedure because they were responding to other patients or duties. The quality and consistency of observation depends on staffing level and the staff's knowledge, experience, and communications practices. ${ }^{18}$ Therefore, staff levels should be increased, ${ }^{19}$ staff should be trained about how to manage of high-risk patients, and clear inpatient management policies should be created and disseminated. ${ }^{17,20}$

Although patients' belonging and storage areas are generally regularly inspected, ward should begin collecting unnecessary underwear and uniforms that can be used as method of suicide. Bedding such as covers and sheets should not be allowed in seclusion rooms. Policies on banned items have been criticized as inconsistent because they are based on each facilities' past events. ${ }^{21}$ It may be useful for physicians and safety supervisors to share information about medical accident and modify their regulations based on that information.

Approximately $80 \%$ of suicides occurred within three months of admission and the median day of suicide attempt was 14 days after admission. Previous studies have produced similar results. ${ }^{12,22}$ The suicidal risk for patients with schizophrenia remains elevated for longer after admission than patients with depression, ${ }^{23}$ so the suicide risk of patients with schizophrenia should be regularly reassessed.

Unlike previous studies, ${ }^{24,25}$ accidents were more likely to occur during weekdays. The staffs have to handle a lot of duties
Table 6. Timing of the accident by combination of day of week and time of day

\begin{tabular}{lccc}
\hline \multicolumn{1}{c}{ Time } & $\begin{array}{c}\text { Total number of } \\
\text { accidents }\end{array}$ & $\begin{array}{c}\text { Number of } \\
\text { deaths }\end{array}$ & $\begin{array}{c}\text { Number of } \\
\text { injuries }\end{array}$ \\
\hline Weekday daytime & 26 & 17 & 9 \\
Weekday night & 30 & 21 & 9 \\
Weekend daytime & 7 & 3 & 4 \\
Weekend night & 15 & 10 & 5 \\
Weekday & 4 & 1 & 3 \\
Weekend & 1 & 0 & 1 \\
Unknown & 2 & 0 & 2 \\
\hline
\end{tabular}

for admission, discharges, and interventions during weekdays. Also the higher rate of accidents at weekdays might be the result of a staff shortage. When compared with other OECD countries with the same levels of GDP like Canada and Brazil, the number of psychiatrists per 1,000 population in Korea is 0.07 in 2016 while the average number in Canada or Brazil is 0.17 . And the number of total mental health worker per 1,000 population is below than the average of high-income countries. ${ }^{26}$ Backup system and clear assignment of duties will reduce staff work overload and guarantee adequate level of observation. And studies for sufficient qualification and number of staff will be required.

This study was limited in that it was only based on partial information of accident, facility regulation, and facility characteristics, so it was impossible to inspect safety and security policies in detail. In addition, the cases were anonymized, so it was impossible to analyze the ages of the defendants, which would likely correspond to their level of experience and whether they had professional liability insurance, which would reduce the burden of the lawsuit. Relevant patient characteristics that might be revealed in psychiatric interview records, nursing records, medical exams, and psychological test results were also not tested in this study. Some of total 
accidents were included because only civil lawsuits were analyzed, but it is difficult to obtain medical dispute data, so this study can serve as a valuable fundamental data source which inpatient facility managers can draw on to prevent medical accidents.

Future studies should analyze total accidents to better understand psychiatric inpatient ward accidents which cause patient injuries. Psychiatric facilities can voluntarily report laboratory results, medication prescriptions, nursing records, interview records and psychological test results, so it is possible to consistently understand patient and institutional factors that influence occurrence of accidents that cause patient injuries.

In conclusion, this study analyzed civil lawsuits filed over medical accidents in inpatient mental health units that resulted in patient injury. Psychiatrists can reduce the number of these accidents by closely managing high-risk patients and modifying ward environment. Many parts of ward can be used as weapons or suicide methods, so removing anchor points and installing proper locking system and barriers will reduce inpatient suicide. If patients are allowed to leave the ward, guards or staffs should accompany them and security cameras should be installed over windows.

\section{Acknowledgments}

\section{None}

\section{Conflicts of Interest}

The authors have no potential conflicts of interest to disclose.

\section{Author Contributions}

Conceptualization: Song Ii Ahn, Dong Ho Song. Data curation: Song Ii Ahn. Formal analysis: Song Ii Ahn. Funding acquisition: Song Ii Ahn. Investigation: Song Ii Ahn, Won Lee, Dong Ho Song. Methodology: Won Lee. Project administration: Dong Ho Song. Resources: Song Ii Ahn. Software: Song Ii Ahn. Supervision: Won Lee, Dong Ho Song. Validation: Song Ii Ahn, Won Lee. Visualization: Song Ii Ahn. Writing_original draft: Song Ii Ahn. Writing-review \& editing: Won Lee, Dong Ho Song.

\section{ORCID iDs}

$\begin{array}{ll}\text { Song Ii Ahn } & \text { https://orcid.org/0000-0003-2418-736X } \\ \text { Won Lee } & \text { https://orcid.org/0000-0002-6948-6948 } \\ \text { Dong Ho Song } & \text { https://orcid.org/0000-0002-9647-3130 }\end{array}$

\section{REFERENCES}

1. Kohn LT, Corrigan JM, Donaldson MS. To Err Is Human: Building a Safer Health System. Washington, DC: National Academies Press; 2000.

2. Lee DP. Current status of medical disputes, prospects and cautions. Korean J Med 2019;94:231-236.

3. Studdert DM, Mello MM, Gawande AA, Gandhi TK, Kachalia A, Yoon C, et al. Claims, errors, and compensation payments in medical malpractice litigation. N Engl J Med 2006;354:2024-2033.

4. Charles SC. Coping with a medical malpractice suit. West J Med 2001; 174:55-58.

5. Studdert DM, Mello MM, Sage WM, DesRoches CM, Peugh J, Zapert $\mathrm{K}$, et al. Defensive medicine among high-risk specialist physicians in a volatile malpractice environment. JAMA 2005;293:2609-2617.
6. Ruskin R, Sakinofsky I, Bagby R, Dickens S, Sousa G. Impact of patient suicide on psychiatrists and psychiatric trainees. Acad Psychiatry 2004; 28:104-110.

7. Alexander DA, Klein S, Gray NM, Dewar IG, Eagles JM. Suicide by patients: questionnaire study of its effect on consultant psychiatrists. BMJ 2000;320:1571-1574.

8. Practice guideline for the assessment and treatment of patients with suicidal behaviors. Am J Psychiatry 2003;160 (11 Suppl):1-60.

9. World Health Organization, World Alliance for Patient Safety. Conceptual framework for the international classification for patient safety. Version 1.1-final technical report [Internet]. Updated January 2009. Available at: http://www.who.int/patientsafety/taxonomy/icps_full_re port. pdf?ua=1. Accessed August 5, 2020.

10. Modlin HC. Forensic psychiatry and malpractice. Bull Am Acad Psychiatry Law 1990;18:153-162.

11. Williams SC, Schmaltz SP, Castro GM, Baker DW. Incidence and method of suicide in hospitals in the United States. Jt Comm J Qual Patient Saf 2018;44:643-650.

12. While D, Bickley H, Roscoe A, Windfuhr K, Rahman S, Shaw J, et al. Implementation of mental health service recommendations in England and Wales and suicide rates, 1997-2006: a cross-sectional and before-and-after observational study. Lancet 2012;379:1005-1012.

13. Mills PD, Watts BV, Hemphill RR. Suicide attempts and completions on medical-surgical and intensive care units. J Hosp Med 2014;9:182-185.

14. Mills PD, Watts BV, Miller S, Kemp J, Knox K, DeRosier JM, et al. A checklist to identify inpatient suicide hazards in veterans affairs hospitals. Jt Comm J Qual Patient Saf 2010;36:87-93.

15. Watts BV, Shiner B, Young-Xu Y, Mills PD. Sustained effectiveness of the mental health environment of care checklist to decrease inpatient suicide. Psychiatr Serv 2016;68:405-407.

16. Lee MS. The Suicide of the psychiatric patients and the responsibility of the hospital. Korean J Leg Med 1996;20:94-100.

17. Tishler CL, Reiss NS. Inpatient suicide: preventing a common sentinel event. Gen Hosp Psychiatry 2009;31:103-109.

18. Flynn S, Nyathi T, Tham SG, Williams A, Windfuhr K, Kapur N, et al. Suicide by mental health in-patients under observation. Psychol Med 2017;47:2238-2245.

19. Han KT, Kim SJ, Jang SI, Hahm MI, Kim SJ, Lee SY, et al. The outcomes of psychiatric inpatients by proportion of experienced psychiatrists and nurse staffing in hospital: new findings on improving the quality of mental health care in South Korea. Psychiatry Res 2015;229: 880-886.

20. Björkdahl A, Nyberg U, Runeson B, Omérov P. The development of the suicidal patient observation chart (SPOC): Delphi study. J Psychiatr Ment Health Nurs 2011;18:558-561.

21. Bowers L, Crowhurst N, Alexander J, Callaghan P, Eales S, Guy S, et al. Safety and security policies on psychiatric acute admission wards: results from a London-wide survey. J Psychiatr Ment Health Nurs 2002; 9:427-433.

22. Hunt IM, Kapur N, Webb R, Robinson J, Burns J, Turnbull P, et al. Suicide in current psychiatric in-patients: a case-control study The National Confidential Inquiry into Suicide and Homicide. Psychol Med 2007;37:831-837.

23. Bowers L, Banda T, Nijman H. Suicide inside: a systematic review of inpatient suicides. J Nerv Ment Dis 2010;198:315-328.

24. Attenello FJ, Wen T, Cen SY, Ng A, Kim-Tenser M, Sanossian N, et al. Incidence of "never events" among weekend admissions versus weekday admissions to US hospitals: national analysis. BMJ 2015;350:h1460.

25. Kozer E, Scolnik D, Macpherson A, Keays T, Shi K, Luk T, et al. Variables associated with medication errors in pediatric emergency medicine. Pediatrics 2002;110:737-742.

26. National Center for Mental Health. National Mental Health Statistics Pilot Study. 4th Ed. Seoul: National Center for Mental Health; 2018. 